\title{
Teocomunicação
}

Revista de Teologia da PUCRS

Programa de Pós-Graduação em Teologia

Escola de Humanidades

Porto Alegre, v. 49, n. 1, janeiro-junho 2019: e34705

https://doi.org/10.15448/0103-314X.2019.1.34705

\section{A aceitação do ser humano por Deus: A doutrina da justificação em João Duns Scotus com um olhar para Martim Lutero}

\section{The Acceptance of Man by God: The Doctrine of Justification of John Duns Scotus with a View to Martin Luther}

\section{Ludger Honnefelder}

Universität Bonn, Institut für Wissenschaft und Ethik. Bonn, Alemanha.

\section{RESUMO}

Na história da teologia anterior ao tempo de Martim Lutero, é acima de tudo na Escola Franciscana que encontramos uma nova abordagem na direção de um entendimento da atividade salvífica de Deus. João Duns Scotus (1265/1266-1308) foi o pensador franciscano que deu atenção especial e, assim, propôs uma nova estrutura conceitual às doutrinas teológicas da salvação e da graça. Neste estudo, faz-se a tentativa de mostrar possíveis ligações entre a abordagem de Scotus e a de Martim Lutero, no século 16. Lutero oferece uma interpretação da atividade de salvação, de Deus, como justificação do pecador pela graça somente, ao passo que Scotus, pouco mais de dois séculos antes, e sob a pressuposição da sua concepção de Deus como um ente infinito racional e volitivo e como Criador contingente, entende essa atividade como a aceitação do pecador através da misericórdia de Deus somente.

Palavras-chave: João Duns Scotus. Martim Lutero. Justificação. Graça. Aceitação divina. Contingência.

\section{ABSTRACT}

In the history of theology previous to Martin Luther's times, it is above all in the Franciscan School that we find a new approach towards an understanding of God's salvific activity. John Duns Scotus (1265/1266-1308) was the Franciscan thinker that gave special attention and, thus, proposed a new conceptual structure to the theological doctrines of salvation and grace. In this study, there is the attempt of showing possible links between Scotus's and Martin Luther's approach, in the $16^{\text {th }}$ century. Luther offers an interpretation of God's activity of salvation as justification of the sinner through grace alone, whereas Scotus, a little bit more than two centuries before, and under the presupposition of his view of God as a rational and volitional infinite being and as contingent Creator, understands that activity as the acceptance of the sinner through God's mercy alone.

Keywords: John Duns Scotus. Martin Luther. Justification. Grace. Divine acceptance. Contingency. 
Toda teologia que busca a ideia de reforma e que deseja um retorno às fontes da fé tem de lidar com a questão de como deve ser entendida a atividade salvífica de Deus. Na história da teologia anterior a Martim Lutero, é sobretudo a Escola Franciscana que chama a atenção a essa questão. Afinal, o próprio São Francisco queria reformar a vida cristã retornando às fontes da fé cristã no Evangelho. Entre os teólogos franciscanos, João Duns Scotus (1265/1266-1308) foi aquele que dedicou uma atenção especial à relação de Deus para com o ser humano pecador e desenvolveu uma nova estrutura conceitual para entender a atividade salvífica de Deus. Entre os teólogos da Reforma, Martim Lutero foi quem desde o início dedicou atenção especial às doutrinas da salvação e da graça. Enquanto Lutero interpreta a atividade de Deus como justificação do pecador pela graça somente, Scotus a descreve, 200 anos antes, como a aceitação do pecador pela misericórdia de Deus.

Essa sucinta caracterização já sugere um olhar para a doutrina scotista, tendo em vista as convicções teológicas do jovem Martim Lutero. Há até mesmo linhas históricas de Scotus a Lutero, uma vez que o jovem Lutero estudou - entre outros - a obra de Gabriel Biel, cuja teologia foi influenciada pelo scotismo e pelo ockhamismo. Mas não é simples responder à pergunta, em que medida a doutrina de Lutero é historicamente dependente de uma tradição teológica anterior. Assim, eu gostaria de concentrar a minha contribuição na seguinte perspectiva doutrinária: fazer um esboço do modo como Scotus analisa a questão da justificação tendo em vista a abordagem do jovem Lutero.

Foram as preleções que o jovem Martim Lutero, como professor universitário, tinha de dar, a saber, sobre os Salmos, sobre as Epístolas aos Romanos, aos Hebreus e aos Gálatas, que o levaram à convicção de que a justificação do pecador tem de ser entendida como justiça pelo Deus gracioso. Muitos "sola" caracterizam a sua nova percepção: primeiramente, a justificação divina do pecador ocorre "somente pela graça" (sola gratia). Conhecemos essa mensagem central somente pela revelação do amor divino e pela crucificação de Cristo, e isso significa, então, sola scriptura e, respectivamente, solus Christus. A justificação divina se tornará eficaz em mim "somente pela fé" (sola fide). Portanto, o ser humano é ao mesmo tempo uma pessoa justa e um pecador (simul iustus et peccator). Pela fé, porém, ele pode ficar seguro de que Deus o salvou.

Já essa breve enumeração mostra aspectos significativos do entendimento de Lutero acerca da justificação: ele é teocêntrico e cristocêntrico, concebe a justificação como uma relação pessoal entre Deus e o ser humano (destacando a relacionalidade e a pessoalidade), sobretudo como um perdão de nossos pecados a partir da misericórdia e do amor de Deus, interpretando isso, ademais, como um evento mediado pela Palavra da Revelação (verbalidade).

Seguindo a doutrina da graça de Agostinho, os teólogos medievais do século 12 colocaram a seguinte questão: como a graça que Deus dá de modo gratuito e anterior às nossas obras (como gratia praeveniens) pode ser concebida como gratia operans,

\footnotetext{
${ }^{1}$ Quanto às seções 1 e 2, cf. DANZ, Ch. Einführung in die Theologie Martin Luthers, 2013; PESCH, O. H. Theologie der Rechtfertigung bei Martin Luther und Thomas von Aquin. Versuch eines systematisch-theologischen Dialogs, 1967; PESCH, O. H. Gnade und Rechtfertigung am Vorabend der Reformation und bei Luther, in: http://www.uni-heidelberg.de/md/fakultaeten/theologie/oek/forum/13.1.pdf; PESCH, O. H. Rechtfertigung V. Theologie- u. dogmengeschichtlich, col. 889-895.
} 
isto é, como uma graça que realmente muda a natureza humana, ao ponto de que o ser humano vem a ser capaz de amar a Deus?

Para responder a essa pergunta, eles fizeram uso da antropologia de Aristóteles e dos conceitos ontológicos que Aristóteles tinha introduzido. Explicando rapidamente a intepretação deles: a mudança da natureza humana pela graça de Deus tem de ser entendida como um evento cujo efeito é uma nova qualidade, que é possuída pelo ser humano desde então, na forma de um "hábito" (habitus) infuso da sua alma. É esse hábito infuso que dá ao ser humano a capacidade de amar a Deus, o que implica realizar atos meritórios, isto é, atos que são recompensados por Deus com a bem-aventurança eterna.

Até mesmo Tomás de Aquino concebeu a gratia operans como algo que tem como efeito uma nova qualidade habitual na alma humana - uma qualidade que tem de ser entendida como uma disposição ou uma faculdade, a qual pode ser comparada com as virtudes morais. Segundo Aristóteles - assim se lê no relato de Scotus -, as virtudes morais são disposições que nos capacitam a realizar atos virtuosos "fácil, prazerosa, rápida e prontamente"2. Tomás de Aquino usa esse conceito de virtude mesmo para as chamadas virtudes teológicas: fé, esperança e caridade. Mas ele ressalta a diferença entre as virtudes morais e as teológicas. As virtudes morais são o resultado de educação e habituação, isto é, elas são o resultado de ações virtuosas frequentes. Em contraste, as virtudes teológicas são "infusas". Elas devem ser concebidas como dons da graça divina, em particular do Espírito Santo.

Se a chamada graça santificante é concebida como uma qualidade habitual da alma, qualidade essa que é um dom gratuito de Deus - como ela foi entendida por Tomás de Aquino e pelos seus seguidores -, ela é o oposto de uma solução pelagiana, isto é, da convicção de que a graça de Deus é a recompensa por nossos feitos morais. No tempo de Lutero, porém, a linguagem tradicional sobre a graça, utilizando os conceitos de Aristóteles, parece ter sido mal compreendida. O "hábito" (habitus) pareceu ter sido compreendido, em todo caso, como um efeito de realizações morais - e, segundo essa interpretação equivocada, a solução tradicional deve parecer como um tipo de pelagianismo.

João Duns Scotus conhece a doutrina tradicional da justificação divina como uma infusão da graça santificante, mas ele não é simplesmente um continuador daquilo que os seus predecessores pensaram. Do seu ponto de vista, o conceito de justificação divina deve ser entendido de um modo que corresponda à compreensão da atividade de Deus na história humana, bem como ao nosso conceito de contingência.

Segundo Scotus, os dois aspectos estão conectados. A contingência, tal como nós a experimentamos em nosso mundo cotidiano, não é adequadamente explicada quando seguimos a interpretação de Aristóteles e mesmo a de Tomás de Aquino. Ambos pensavam que a contingência é um efeito cosmológico, um efeito da difformitas materiae $^{3}$ no mundo sublunar. Na nova interpretação de Scotus, a contingência significa que um ente ou um evento atualmente existente pode não existir ou pode existir de outro modo no mesmo momento em que existe. Essa nova explicação da contingência, a chamada "contingência sincrônica", leva à pergunta pela causa dela. Scotus argumenta que a causa primeira dos entes e dos eventos contingentes não pode ser outra coisa senão uma causa primeira volitiva livre.

Isso corresponde à seguinte doutrina de Scotus: a causa primeira deve ser concebida como um ente infinito necessariamente dotado de intelecto e vontade. Porque uma

${ }^{2}$ IOANNES DUNS SCOTUS. Opera omnia V, Ordinatio I d. 17, p. 1, q. 1-2, n. 7, 48, 88, p. 142, 158, 181-182.

${ }^{3}$ Isto é, da "deformidade da matéria". N. de R. T. 
vontade infinita, por sua natureza, está "necessariamente no ato correto", a vontade divina "está necessariamente no ato correto de querer aquele objeto que de si há de ser querido retamente" (de necessitate est in actu volendi illud obiectum quod ex se recte volendum). Tal objeto é a essência divina como o bem infinito. Porque a vontade divina é livre como tal e só necessariamente autodeterminada com respeito ao bem infinito, Scotus fala de uma "necessidade espontânea" (necessitas spontanea) em contraste com uma necessidade natural. Portanto, a vontade de Deus deve ser entendida como uma potência racional que age do modo mais perfeito, isto é, no modo da "afecção por justiça" (affectio iustitiae), o que significa que ela quer ou ama o bem em função dele próprio. Se a bondade de Deus é infinita, então deve-se concluir que a sua vontade livre é direcionada para essa bondade infinita com necessidade. O amor de Deus pelo bem tem a forma de um amor a Si mesmo (amare se) livre e necessário - por tudo o que é diferente de si tem a forma de um amor livre e contingente.

Mas se Deus é tal ente infinito, cuja vontade tem de ser concebida como um amor infinito do bem por causa de si mesmo, isso tem consequências para o entendimento das atividades de Deus enquanto criador e redentor. Afinal, como vimos, só o bem infinito é algo que Deus ama com necessidade. Um objeto finito da atividade criadora e redentora de Deus só pode ser querido e amado por Deus de um modo livre, porém contingente. "Nada que está fora da essência de Deus pode ser uma razão (necessária) do seu querer" (nihil extra deum est ipsi ratio volendi) 4 . Scotus, portanto, afirma que "nada criado tem como tal de ser aceito por Deus" (nihil creatum formaliter est a Deo acceptandum). A liberdade de Deus inclui indisponibilidade e soberania.

Portanto, é preciso distinguir entre, por um lado, a ordem que é o objeto do conhecer e do querer livre e necessário de Deus, e esse objeto é somente a essência de Deus e o seu único limite é o princípio de não-contradição - Scotus chama essa ordem de "de potentia absoluta" -, e por outro lado a ordem que diz respeito à atividade de Deus $a d$ extra ${ }^{6}$ e que tem a sua origem na vontade livre e contingente de Deus. Scotus chama essa ordem de "de potentia ordinata". Essa segunda ordem é contingente, mas não arbitrária, pois mesmo a atividade de Deus ad extra deve ser concebida como racional e boa. Deus é "ordinatissime volens", e o que ele quer ad extra é uma "ordenação" (ordinatio).

A atividade de Deus ad extra, isto é, a sua vontade em relação ao mundo criado pode ser considerada, portanto, de acordo com três diferentes instâncias: (1) antes de qualquer ato da vontade, o intelecto divino compreende todo objeto inteligível como possível e torna-os "esse intelligibile". Todos esses assim chamados objetos secundários do intelecto divino são objetos eternos de sua vontade, e é a "complacência" (complacentia) divina que confere a eles esse volibile $e^{9}$ (2) em uma conseguinte volição eficaz, Deus elege contingentemente aquilo que ele quer criar de potentia ordinata. (3) Em um terceiro momento, Deus decide que aqueles seres humanos que estão vivendo no amor a

\footnotetext{
${ }^{4}$ IOANNES DUNS SCOTUS. Opera omnia XXII (ed. L. Vivès), Reportata parisiensia I d. 41, q. un., n. 6, p. 481a.

${ }^{5}$ Quanto às seções 3 e 4, cf. HONNEFELDER, L. Johannes Duns Scotus, p. 91-102; p. 113-126; HONNEFELDER, L. Scientia transcendens: Die formale Bestimmung der Seiendheit und Realität in der Metaphysik des Mittelalters und der Neuzeit (Duns Scotus - Suárez - Wolff - Kant-Peirce), p. 56-108; p. 158-199; HONNEFELDER, L. Freiheit und Rationalität. Die neue Verhältnisbestimmung von Verstand und Wille bei Duns Scotus, p. 165-182.

${ }^{6}$ Isto é, "para fora [de Si]". N. de R. T.

7 Isto é, "volente [ou: volitivo] do mais ordenado modo". N. de R. T.

${ }^{8}$ Isto é, "ser inteligível". N. de R. T.

${ }^{9}$ Isto é, "ser volível” ou "ser querível”. N. de R. T.
} 
Deus serão recompensados com a salvação, isto é, com uma vida eterna em comunhão com Deus. A indisponibilidade e a soberania de Deus só podem ser resguardadas se mesmo a amorosa aceitação divina daquele ser humano que vive em amor a Deus ocorrer de um modo livre e contingente, isto é, de acordo com a sua potentia ordinata. O fato de que Deus recompensa os atos meritórios do ser humano com o dom de uma vida eterna tem se de considerado, como tal, como uma aceitação contingente, isto é, como uma graça não merecida. E essa aceitação se refere à pessoa, não só às suas obras.

É significativo que Scotus está convencido de que a vida humana que é vivida no amor (caritas) de Deus e cujas ações meritórias serão imerecidamente recompensadas por Deus com a vida eterna não é uma realização exclusiva do ser humano que necessariamente será recompensada com a graça. Em sua perspectiva, a vida humana vivida no amor (caritas) de Deus é um efeito de duas causas parciais: a caritas divina e o amor humano. Elas operam juntas na produção do efeito da justificação e recompensa divinas: a graça divina preveniente (gratia operativa) e a vontade humana. Com respeito ao ato enquanto ato, a vontade humana tem a causalitas prior ${ }^{10}$; com respeito à meritoriedade da atividade humana, a caritas divina é a "causa principal" (causa principalior $)^{11}$. $\mathrm{O}$ ato de amor só pode ser chamado de meritório na medida em que há uma referência à vontade divina que o aceita ${ }^{12}$.

Mas o que dizer sobre a doutrina da graça divina como um hábito infuso, doutrina essa que domina a discussão medieval sobre a justificação desde o século 12 e que, como vimos, é ainda um elemento central da solução de Tomás de Aquino? Scotus também a recebe, mas só depois de uma longa ponderação dos argumentos a favor e contra. Não apenas a discussão - muito detalhada -, mas em particular os argumentos contrários ${ }^{14}$ nos levam à conclusão de que, na perspectiva de Scotus, a interpretação da graça santificante como um hábito na alma humana não deve ser considerada como um elemento necessário para entender a atividade santificadora de Deus.

Em um dos argumentos que Scotus apresenta contra a assunção de que a graça santificante seja um hábito infuso, ele menciona, na premissa, que, devido à sua natureza, a remissão dos nossos pecados tem, como tal, de preceder à dádiva da graça ${ }^{15}$. Afinal, assim é argumentado, para se tornar "amigo" (amicus) é preciso primeiramente parar de ser "inimigo" (inimicus) $)^{16}$. Scotus então responde que o não-inimigo não é ainda amigo, o que fala em favor da assunção da graça como hábito ${ }^{17}$. Como um todo, porém, o argumento fala por si mesmo e não faz da hipótese do hábito um elemento indispensável. Isso é assim porque, se a remissão dos nossos pecados já é a justificação por Deus, então não é necessário assumir uma mudança real em nossa alma na forma da infusão de um hábito particular de graça.

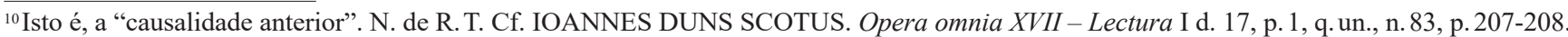

${ }^{11}$ IOANNES DUNS SCOTUS. Opera omnia XVII - Lectura I d. 17, p. 1, q. un., n. 79, p. 206.

${ }^{12}$ IOANNES DUNS SCOTUS. Opera omnia XVII - Lectura I d. 17, p. 1, q. un., n. 89, p. 209.

${ }^{13}$ Quanto à seção 5, cf. DETTLOFF, W. Die Lehre von der acceptatio divina bei Johannes Duns Scotus unter besonderer Berücksichtigung der Rechtfertigungslehre, 1954; DETTLOFF, W. Zur Beurteilung der skotischen Akzeptationslehre, p. 144-146; DETTLOFF, W. Die Entwicklung der Akzeptations- und Verdienstlehre von Duns Scotus bis Luther mit besonderer Berücksichtigung der Franziskanertheologen, 1963; DETTLOFF, W. Die Akzeptationslehre des Johannes Duns Scotus in der vorreformatorischen Theologie, p. 195-211; PANNENBERG, W. Das Verhältnis zwischen der Akzeptationslehre des Duns Scotus und der reformatorischen Rechtfertigungslehre, p. 213-218; CROSS, R. Duns Scotus, p. 107-111.

${ }^{14}$ Ocupando 4 páginas, in: IOANNES DUNS SCOTUS. Opera omnia V, Ordinatio I d. 17, p. 1, q. 1-2, n. 113-124, p. 195-200.

${ }^{15}$ IOANNES DUNS SCOTUS. Opera omnia V, Ordinatio I d. 17, p. 1, q. 1-2, n. 120, p. 198.

${ }^{16}$ IOANNES DUNS SCOTUS. Opera omnia V, Ordinatio I d. 17, p. 1, q. 1-2, n. 162, p. 216.

${ }^{17}$ IOANNES DUNS SCOTUS. Opera omnia V, Ordinatio I d. 17, p. 1, q. 1-2, n. 163, p. 216.
} 
Mesmo que, ao final da discussão, Scotus concorde com a assunção tradicional da graça como um hábito infuso da nossa alma, o foco da sua interpretação da justificação não é - como já havia mencionado Wolfhart Pannenberg, na sua interpretação da doutrina de Scotus - a explicação ontológica da graça como um hábito infuso da nossa alma, mas a explicação relacional da graça como uma "aceitação divina" (acceptatio divina), isto é, como uma ação forense, na qual a misericórdia de Deus decide não levar em conta os nossos pecados - o que já é o início da justificação divina.

A razão de ter colocado o foco na relação entre Deus e o ser humano é o já mencionado entendimento da soberania divina por Scotus. Se considerarmos a vontade divina de potentia absoluta, isto é, independentemente da ordem particular que ele tinha decidido de potentia ordinata, Deus poderia, assim argumenta Scotus, até mesmo ter aceitado o ser humano tal como ele existe naturalmente (existentem in puris naturalibus) ${ }^{18}$, isto é, sem nenhum ato meritório. E não seria a sua "natureza pura" (natura pura) ou os seus atos naturais que mereceriam a aceitação divina - esse seria o erro de Pelágio -, mas somente a vontade soberana de Deus.

6.

Chego, agora, a algumas conclusões:

Se tentarmos comparar o entendimento de Lutero acerca da justificação "pela graça somente" e o foco de Scotus na justificação como aceitação divina, podemos encontrar alguns aspectos, de acordo com os quais a interpretação de Scotus é bastante próxima àquela de Lutero.

(a) É a nova concepção de Scotus acerca do ente como intensidade e do intelecto e da vontade como perfeições puras que o permite que ele conceba Deus como um ente cuja infinitude inclui as perfeições puras "intelecto" e "vontade". Uma vez que, entre as perfeições, a vontade é a mais elevada, a transcendência de Deus tem de ser considerada como a transcendência da sua vontade, isto é, a transcendência de uma liberdade que só é determinada pela afecção pelo bem. As ações divinas em relação a bens finitos têm, portanto, de ser entendidas como uma atividade livre e contingente, cuja origem é pura e imerecida graça. A justificação do pecador é um evento teocêntrico, isto é, uma ação da parte de Deus.

(b) Se a soberania de Deus tem de ser concebida como a transcendência de uma liberdade que só é determinada pela afecção pelo bem, é consequente concluir que, de acordo com a potentia ordinata de Deus, a aceitação do pecador consiste na justificação, por Deus, "somente pela graça", do ser humano pecador e na recompensa, por Deus, dos atos meritórios do ser humano com a felicidade eterna.

(c) Na perspectiva de Scotus, o destinatário da atividade justificante e santificante de Deus é a pessoa humana singular, em sua liberdade. A aceitação de Deus, portanto, torna-se eficaz apenas se ela é livremente aceita pela pessoa humana. Assim, Scotus é capaz de interpretar a doutrina tradicional da graça como hábito infuso, no sentido de uma causalidade concorrente, na qual a graça preveniente de Deus é a causa principal da meritoriedade - uma interpretação que salvaguarda o caráter interpessoal da atividade justificadora de Deus e busca evitar o pelagianismo. O dom divino de uma vida eterna diz respeito à pessoa em sua totalidade.

(d) Dado que Scotus concebe a justificação como uma atividade forense da parte de Deus, a aceitação divina do pecador é entendida, primariamente, como remissão

${ }^{18}$ IOANNES DUNS SCOTUS. Opera omnia $V$, Ordinatio I d. 17, p. 1, q. 1-2, n. 160, p. 215. 
dos seus pecados. Aceitar o pecador como "amigo" (amicus) pressupõe fazê-lo, antes, "não-inimigo" (non-inimicus). A ideia de que, de acordo com Scotus, o Deus soberano pode, de potentia absoluta, recompensar o pecador sem atos meritórios mostra claramente a convicção do Doutor Sutil de que a justificação do pecador tem de ser entendida como uma aceitação, cuja origem é a irrestrita misericórdia de Deus.

(e) A visão de Scotus sobre a salvação não é somente teocêntrica, mas é também cristocêntrica. Se Deus age ad extra de modo contingente, mas ordenadíssimo, a criação e a salvação podem ser entendidas como partes de uma história, cuja destinação consiste na encarnação e na morte de Cristo (a tese de Scotus da predestinação absoluta de Cristo) - uma história que se torna eficaz, para a humanidade, pela fé na palavra revelada de Deus (verbalidade).

(Tradução de Cesar Ribas Cezar, UNIFESP; revisão técnica da tradução por Roberto Hofmeister Pich, PUCRS)

\section{REFERÊNCIAS}

CROSS, Richard. Duns Scotus. New York: Oxford University Press, 1999.

DANZ, Christian. Einführung in die Theologie Martin Luthers. Darmstadt: Wissenschaftliche Buchgesellschaft, 2013.

DETTLOFF, Werner. Die Akzeptationslehre des Johannes Duns Scotus in der vorreformatorischen Theologie. In: BÉRUBÉ, Camille (ed.). Regnum Hominis et Regnum Dei: Acta Quarti Congressus Scotistici Internationalis. Roma: Societas Internationalis Scotistica, 1978. v. 1, p. 195-211.

DETTLOFF, Werner. Die Entwicklung der Akzeptations- und Verdienstlehre von Duns Scotus bis Luther mit besonderer Berücksichtigung der Franziskanertheologen. Münster: Aschendorff, 1963.

DETTLOFF, Werner. Die Lehre von der acceptatio divina bei Johannes Duns Scotus unter besonderer Berücksichtigung der Rechtfertigungslehre. Werl: Coelde, 1954.

DETTLOFF, Werner. Zur Beurteilung der skotischen Akzeptationslehre. Wissenschaft und Weisheit, Düsseldorf, v. 16, p. 144-146, 1953.

HONNEFELDER, Ludger. Freiheit und Rationalität: die neue Verhältnisbestimmung von Verstand und Wille bei Duns Scotus. In: HONNEFELDER, Ludger. Was ist Wirklichkeit? Zur Grundfrage der Metaphysik. Paderborn: Schöningh, 2016. p. 165-182.

HONNEFELDER, Ludger. Johannes Duns Scotus. München: Verlag C. H. Beck, 2005.

HONNEFELDER, Ludger. Scientia transcendens: die formale Bestimmung der Seiendheit und Realität in der Metaphysik des Mittelalters und der Neuzeit (Duns Scotus - Suárez - Wolff - Kant - Peirce). Hamburg: Felix Meiner Verlag, 1990.

IOANNES DUNS SCOTUS. Opera omnia $V$-Ordinatio liber primus: a distinctione undecima ad vigesimam quintam. Civitas Vaticana: Typis Polyglottis Vaticanis, 1959.

IOANNES DUNS SCOTUS. Opera omnia XVII - Lectura in librum primum sententiarum: a distinctione octava ad quadragesimam quintam. Civitas Vaticana: Typis Polyglottis Vaticanis, 1966.

IOANNES DUNS SCOTUS. Opera omnia XXII. Paris: Ed. L. Vivès, 1891-1895. 
PANNENBERG, Wolfhart. Das Verhältnis zwischen der Akzeptationslehre des Duns Scotus und der reformatorischen Rechtfertigungslehre. In: BÉRUBÉ, Camille (ed.). Regnum Hominis et Regnum Dei: Acta Quarti Congressus Scotistici Internationalis. Roma: Societas Internationalis Scotistica, 1978. v. 1, p.213-218.

PESCH, Otto Hermann. Gnade und Rechtfertigung am Vorabend der Reformation und bei Luther. Disponível em: http://www.uni-heidelberg.de/md/fakultaeten/theologie/oek/forum/13.1.pdf. Acesso em: 15 fev. 2017.

PESCH, Otto Hermann. Rechtfertigung V. Theologie- u. Dogmengeschichtlich. In: KASPER, Walter (Hrsg.). Lexikon für Theologie und Kirche. Freiburg: Herder, 1999. col. 889-895.

PESCH, Otto Hermann. Theologie der Rechtfertigung bei Martin Luther und Thomas von Aquin: Versuch eines systematisch-theologischen Dialogs. Mainz: Matthias-Grünewald-Verlag, 1967.

Recebido: 02/07/2019

Aceito: 24/07/2019

Publicado em: 31/10/2019

\section{Autor:}

LUDGER HONNEFELDER

Universität Bonn, Institut für Wissenschaft und Ethik. Bonn, Alemanha.

E-mail: roberto.pich@pucrs.br

$\triangle$ Endereço:

Bonner Talweg 57

53113 - Bonn, Alemanha 